\title{
Efficacy of a New-generation Platelet-rich Fibrin in the Treatment of Periodontal Intrabony Defects: a Randomized Clinical Trial
}

Boroka Klara Csifo-Nagy ( $\sim$ drcsifo@gmail.com )

Semmelweis Egyetem Fogorvostudomanyi Kar https://orcid.org/0000-0001-9454-2916

Eleonora Solyom

Semmelweis Egyetem Fogorvostudomanyi Kar

Vera Lili Bognar

Semmelweis Egyetem Fogorvostudomanyi Kar

Annamaria Nevelits

Semmelweis Egyetem Fogorvostudomanyi Kar

Ferenc Dori

Semmelweis Egyetem Fogorvostudomanyi Kar

Research article

Keywords: intrabony defects, periodontal healing, advanced platelet-rich fibrin, enamel matrix derivatives

Posted Date: May 18th, 2021

DOI: https://doi.org/10.21203/rs.3.rs-525471/v1

License: (c) (i) This work is licensed under a Creative Commons Attribution 4.0 International License.

Read Full License

Version of Record: A version of this preprint was published at BMC Oral Health on November 15th, 2021.

See the published version at https://doi.org/10.1186/s12903-021-01925-1. 


\section{Abstract}

Background: The aim of the study was to clinically evaluate the healing of intrabony defects after treatment with a new generation of platelet-rich fibrin (A-PRF+) respect to enamel matrix derivatives (EMD).

Methods: Thirty (30) intrabony defects of 18 patients (9 males, 9 females) were randomly treated with APRF+ (test, $n=15$ ) or EMD (control, $n=15$ ). The following clinical parameters were recorded at baseline and 6 months after surgery: pocket depth (PD), gingival recession (GR) and clinical attachment level (CAL). After debridement the intrabony defects were filled with A-PRF+ in the test group, respectively with EMD in the control group, and fixed with sutures to ensure wound closure and stability.

Results: Both treatment methods resulted in statistically significant PD reductions, respectively CAL gains six months post-operatively. No statistically significant differences were found between the two groups as the mean CAL gain was $2.33 \pm 1.58 \mathrm{~mm}$ in the A-PRF+ group, respectively $2.60 \pm 1.18 \mathrm{~mm}$ in the EMD group $(p<0.001)$.

Conclusion: Within the limits of this study the new-generation platelet-rich fibrin seems to be as clinically effective as EMD in the surgical treatment of intrabony defects. Treatment with A-PRF+ or EMD resulted in reliable clinical outcomes. The use of A-PRF+ as a human autologous product can give a positive impact on periodontal healing.

Clinical Relevance: A-PRF+ may be suitable for the treatment of intrabony periodontal defects.

Trial registration number (TRN): NCT04404374 (ClinicalTrials.gov ID)

Date of registration: 19.05 .2020$. retrospectively registered

\section{Background}

The main goal of the comprehensive periodontal treatment is to eliminate inflammation and to prevent further destruction of the periodontium, as well as to achieve long-term sustainable condition. Over the past decades, significant efforts have been made to develop materials and also surgical techniques that can predictably contribute to periodontal regeneration [1]. Nowadays, regenerative periodontal therapy can only restore a part of the original tissue to some extent, while the complete periodontal restoration remains idealistic [2]. More than 20 years have passed since enamel matrix derivatives (EMD) were introduced to enhance periodontal regeneration by mimicking the formation of periodontal attachment tissues. They play an important role as chemical barriers and biological mediators in periodontal regeneration and healing [3]. Advances in cell and molecular biology have contributed to an increased understanding of wound healing. There is evidence that polypeptide growth and differentiation factors (GDF's) can support wound healing and regeneration by regulating chemotaxis, differentiation, proliferation of cells and matrix synthesis. However, only a few factors have reached clinical evaluation, 
earlier research has just targeted finding of the optimal dosage and the combination of growth and differentiation factors [4]. Data from long-term follow-up clinical studies demonstrated that treatment of deep periodontal intrabony defects with EMD resulted in a significant increase of clinical attachment gain and bone fill compared to the "open flap debridement" [5-8]. In periodontal application of chemicalbiological factors, a new period followed by the introduction of autologous platelet concentrates (PlateletRich Plasma - PRP, Platelet-Rich Gel - PRG, Platelet-Rich Fibrin - PRF) [9-13]. A strategy to promote wound healing is to amplify and accelerate the effect of released growth factors (GF's), which can accelerate the healing of bone defects and promote periodontal regeneration. The simplest way to achieve these goals is to activate the local release of platelet-derived growth factors, which are common triggers in almost all wound healing processes. A method for the intraoral application of concentrated autologous products (CAP) has been developed for more than two decades. The use of PRP is based on the effect of growth factors released from concentrated platelets on healing and tissue regeneration [14-15].

With the advancements made in platelet - rich concentrates formulations over the past decade, PRF has been introduced and utilized as a supra-physiological concentration of autologous growth factors without necessitating the use of anticoagulants $[13,16]$. The PRF is a product that enhances wound healing, unlike PRP. The beneficial effects of PDGF's, TGF-beta (platelet-derived growth factor, transforming growth factor beta) and other GF's released from platelets can be recorded not only in the early stages of wound healing, but also its effects last longer and appear at a slower rate $[9,17]$.

A new generation of platelet-rich fibrin formulation has been introduced in 2014 by Choukroun et al., the Advanced Platelet Rich Fibrin (A-PRF), which is obtained by a lower speed centrifugation [18]. Standard leukocyte-rich PRF (L-PRF) and A-PRF obtained through the experimental "low-force modified procedure" are ideal sources of leukocytes that act directly on the release of chemokines and growth factors. Although A-PRF "traps" the same number of leukocytes as L-PRF and releases the same amount of inflammatory cytokines, it contains higher amounts of PDGF and VEGF [19]. Another study found that APRF also contained significantly more TGF- $\beta 1, E G F$, and IGF, and had shown significantly higher human fibroblast migration and proliferation than L-PRF. From this study, it appears that reducing the centrifugation rate favors the growth factors released from the PRF clot [20]. The new version of A-PRF (2017) is the A-PRF + product, in which case the centrifugation takes even less time (low-speed + time procedure). Described by Fujioka-Kobayashi et al., the newer formulation of A-PRF (A-PRF + means not only lower centrifugation speed, but also less time $-1300 \mathrm{rpm}$ for $8 \mathrm{~min}$ ) and demonstrated an increased growth factor release of TGF-beta1, PDGF-AA, PDGF-AB, PDGF-BB, VEGF, IGF, and also EGF. When compared to L-PRF and A-PRF, A-PRF + it has demonstrated a significant increase in growth factor release within either 1,3 , or 10 days [20]. In conclusion, results show that the total growth factor release could be enhanced by reducing both centrifugation speed and time in A-PRF+. The examination of the fibrin network in terms of structural integrity, A-PRF + showed similar porosity to A-PRF, furthermore over the entire clot the cellular distribution pattern showed evenly dispersed platelets. These observations emphasize the improved regenerative capacity of advanced PRF matrices. 
The research and application of EMD as practically non-human biological mediators (Emdogain $\circledast$, Straumann ${ }^{\circledR}$, Basel, Switzerland) in periodontal regenerative surgery, although dating back more than two decades still raises a number of unanswered or ambiguously answered questions. Research on the use of autologous growth and differentiation factors as well as recombinant growth factors (rhGF's) as biological mediators in periodontal regenerative procedures has a relatively shorter history and offers many additional opportunities for researchers. Examining the new generation of PRF is an even more topical task.

\section{Methods}

Our aim was to investigate the further role of human autologous platelet concentrates in periodontal healing and regeneration. We tested the role and clinical applicability of a new generation of platelet-rich fibrin, "Advanced Platelet-Rich Fibrin (A-PRF+)", in periodontal wound healing. The clinical data obtained during the study were compared with the results of a well-known and successfully applied regenerative method. The null hypothesis of the study was whether an autologous material (A-PRF+) can be a reliable alternative in surgery of intrabony defects.

\section{Study design}

This study was planned as a randomized, controlled, prospective clinical trial, performed in accordance with the Helsinki Declaration of 1975, as updated in 2013, and the protocol was approved by the ethics committee of the Semmelweis University Budapest (SE TUKEB: 254/2017). The study protocol was retrospectively registered at ClinicalTrials.gov with ID number NCT04404374.

The study was conducted in the Department of Periodontology, Semmelweis University, Budapest, Hungary. It was initiated in June 2018 and completed in November 2019 by the same experienced periodontist (BCSN). Each participant has been explained the risks, benefits, and the procedure in his/her native language and written informed consent was obtained.

\section{Study population}

According to the new classification proposed by the World Workshop on the Classification of Periodontal and Peri-Implant Diseases and Conditions (2017), the patients were classified into stage III. periodontitis [21]. The patients initially received cause-related periodontal therapy, consisting of oral hygiene instruction, motivation and sub-gingival scaling/root planing under local anaesthesia. The patients were consecutively enrolled when the following inclusion criteria was met: 1) no systemic diseases that could influence the outcome of the therapy; 2) no smoking [22]; 3) good level of oral hygiene with Full-Mouth Bleeding Score < 20\% [23] and Full- Mouth Plaque Index Score < 20\% [24]; 4) presence of a minimum one or more 2-, 3-, or combined 2-3-wall intrabony defect with a defect angle of 20-40 (+/-5) degrees, as the radiographic defect angle influences the outcome of regenerative surgical therapy in intrabony defects [25] and with a minimum probing depth (PD) of $6 \mathrm{~mm}$ and intrabony component of a minimum $4 \mathrm{~mm}$.

\section{Clinical parameters}


The following clinical parameters were assessed at baseline ( 1 week before surgery) and at six months after the surgery, using the same type of periodontal probe (UNC-15, Hu-Friedy, Chicago, IL, USA): FullMouth Plaque Score (FMPS) [24] and Full-Mouth Bleeding Score (FMBS) [23], pocket depth (PD), gingival recession (GR), clinical attachment level (CAL) and transgingival bone sounding (BS). The primary outcome was CAL gain. Radiographs were performed with "long cone" technique before surgery, and 6 month post-surgically. The clinical measurements were made at six sites per tooth, mesio-buccal, midbuccal, disto-buccal, mesio-lingual, mid-lingual, and disto-lingual, by the same experienced, calibrated investigator (ES), and the highest PD value was taken in consideration.

\section{Blinding and calibration}

The examiner was not aware of the type of treatment rendered in any of the cases. The measurements were rounded up to the nearest millimeter.

To calibrate the examiner five patients were used, each showing 10 teeth (single and multi- rooted) with PDs $>6 \mathrm{~mm}$ on at least one aspect of each tooth. The examiner evaluated the patients on two separate occasions, 48 hours apart. Calibration was accepted if $>90 \%$ of the recordings could be reproduced within 1.0-mm difference.

\section{Randomization}

The defects were randomly allocated by computerised random number generator (https://www.sealedenvelope.com) and treated with either A-PRF+ (test group) and EMD (control group).

\section{Preparation of A-PRF+}

Immediate before surgery A-PRF + was prepared for the test group using a commercially available PRF Kit [Process for PRF® (A-PRF), J. Choukroun, Nice, France] and "Process for PRF Duo" (Choukroun) centrifuge. Cubital venous blood was drawn from the patient without the addition of anticoagulant into two $10 \mathrm{ml}$ vacuum tubes (A-PRF + tube, Choukroun 2017) and immediately centrifuged at $1300 \mathrm{rpm}$ for 8 minutes, then allowed to rest for 5 minutes [20]. During centrifugation, 3 layers are formed in the tube at the start of the coagulation cascade. The top layer is the Platelet-Poor Plasma (PPP), the middle layer is the Platelet-Rich Fibrin "clot" (PRF) is to be used, and the bottom layer is the Red Blood Cells (RBC's) layer. The PRF "clot" still in the gel condition is removed from the tube, cleaned of red blood cells and used as a gel.

\section{Surgical procedure}

Surgery was performed by a single experienced operator (BCSN). After administration of local anesthesia intracrevicular incisions were performed extending to the adjacent teeth, with the additional precaution to preserve the maximum of interdental gingival tissue. Full-thickness buccal and oral extended flaps were raised, and all granulation tissue was removed from the defect without bone recontouring. The roots were thoroughly scaled and planed by means of hand and ultrasonic instruments. After defect debridement, in the test group A-PRF + was applied. (Fig. 1.) In the control group after debridement the root surface 
adjacent to the defect was conditioned for 2 minutes with 24\% ETDA gel (pH 6.7) (PrefGel, Straumann®, Basel, Switzerland) [26]. The defect and the adjacent mucoperiosteal flap were then thoroughly rinsed with sterile saline to remove all EDTA residue, and then Straumann ${ }^{\circledR}$ Emdogain $®$ was applied. (Fig. 2.) Finally, the flap was repositioned coronally and closed thoroughly with 5.0. non-absorbable modified vertical or horizontal mattress sutures (Dafilon® ${ }^{\circledR}$ 5.0. monofilament and uncoated polyamide, B. Braun Surgical S.A. Barcelona, Spain).

\section{Postoperative care}

All patients have received antibiotics for a week, two times daily (Augmentin Duo, $875 \mathrm{mg}$ amoxycillin/125mg clavulanic acid, GlaxoSmithKline, Brentford, United Kingdom). The postoperative care consisted of $0.2 \%$ chlorhexidine (Curasept ADS 220, Curaden AG, Kriens, Switzerland) rinses two times daily for 3 weeks. Patients were advised not to use mechanical means of plaque control in the surgical area for more weeks. Sutures were removed 14 days after surgery. Instructions for maintenance of proper oral hygiene were reinforced. Study participants were scheduled for a follow-up visit weekly for onemonth post-surgery and subsequently at three and respectively six months interval.

\section{Statistical analyses}

For the clinical parameters, data was evaluated using descriptive analysis with results illustrated as mean $\pm S D$, range at baseline and 6 months interval. The statistical package Stata (StataCorp. 2017. Stata Statistical Software: Release 15. College Station, TX: StataCorp LLC) was used for data handling and analysis.

Defects identified (rather than patients) were treated as the unit of observation. Generally, two samples of 15 observations each are adequately powered (80\%) to detect a between-groups difference of 1.06 standard deviations (SD) in a continuous variable, assuming equal SDs across groups. Post-hoc power calculations were carried out for between-groups comparisons at 6 months and within-group comparisons ( 6 months vs baseline) for each outcome. Within-group changes were evaluated using paired t-tests (or Wilcoxon's matched-pairs signed-ranks test if parametric assumptions were not satisfied), and between-groups comparisons were made using two-sample t-tests (or Wilcoxon's rank-sum tests if parametric assumptions were not satisfied). $P$ values $<0.05$ were considered to indicate statistical significance. Regarding frequency distribution changes from baseline to 6 months were categorized in each outcome as decrease, no change, and increase. To compare the two groups in terms of these, Fisher's exact test was used. (Table 4.)

\section{Results}

\section{Participants and Recruitment}

The study flowchart is illustrated on Fig. 3. This study has enrolled thirty (30) intrabony defects of 18 non-smoking patients (nine males and nine females) age $55.5+/-14.5$ years, suffering from chronic periodontitis. Among patients the defect distribution was proportional. Baseline and postoperative FMBS 
and FMPS values were comparable, FMBS values decreased after surgery. (Table 1.) Post-hoc power calculations for between-groups comparison of $\mathrm{PD}$ and BS values were not estimable because the two group means at 6 months were identical. For GR and CAL values, there was an estimated $11 \%$ power. For within-group comparisons, power estimates of at least $99.8 \%$ were obtained for all outcomes.

Table 1

Baseline and postoperative FMBS and FMPS values

\begin{tabular}{|lll|}
\hline & A-PRF+ & EMD \\
\hline FMBS & & \\
\hline Baseline & $23 \%$ & $22 \%$ \\
\hline 6 months postop. & $10 \%$ & $12 \%$ \\
\hline FMPS & & \\
\hline Baseline & $17 \%$ & $18 \%$ \\
\hline 6 months postop. & $16 \%$ & $19 \%$ \\
\hline
\end{tabular}

All patients have completed the respective study. The postoperative healing was uneventful in all cases. No complications such as allergic reactions, abscesses or infections were identified throughout the entire study period. The trial was terminated after the completion of the six-month follow-up and analysis of the data of 30 intrabony defects, which displayed a comparable distribution and configuration in the two groups. (Table 2.) 
Table 2

Distribution and configuration of treated defects

\begin{tabular}{|lll|}
\hline & A-PRF+ & EMD \\
\hline Tooth Location & & \\
\hline Maxilla & 6 & 7 \\
\hline Mandible & 9 & 8 \\
\hline Anterior teeth & 4 & 3 \\
\hline Premolars & 6 & 5 \\
Molars & 5 & 7 \\
\hline Defect Configuration & & \\
\hline 2-wall & 4 & 3 \\
\hline 3-wall & 4 & 4 \\
\hline 2-3-wall combined & 7 & 8 \\
\hline
\end{tabular}

No statistically significant differences were found between the two groups regarding the mean values of the baseline clinical parameters. After 6 months, the mean PD has decreased significantly in both groups compared to baseline data $(p<0.001)$. The mean PD reduction was $4.67 \pm 0.62 \mathrm{~mm}$ in the A-PRF + group and identically $4.67 \pm 0.62 \mathrm{~mm}$ in the EMD group. No statistically significant difference between the groups was found. (Table 3.) 
Table 3

Within group comparisons / Intergroup changes (significance: $p<0.05$ )

\begin{tabular}{|c|c|c|c|c|c|}
\hline & Baseline & $\begin{array}{l}6 \text { months } \\
\text { postop. }\end{array}$ & $p$ & Diff. & $\mathbf{p}$ \\
\hline \multicolumn{6}{|l|}{ PD } \\
\hline A-PRF+ & $8.27 \pm 1.58$ & $4.67 \pm 0.62$ & $\begin{array}{l}p< \\
0.0001\end{array}$ & $-3.6 \pm 1.68$ & $\begin{array}{l}p= \\
0.0000\end{array}$ \\
\hline \multirow[t]{2}{*}{ EMD } & $8.13 \pm 1.60$ & $4.67 \pm 0.62$ & $\begin{array}{l}\mathrm{p}< \\
0.0001\end{array}$ & $\begin{array}{l}-3.46 \pm \\
1.30\end{array}$ & $\begin{array}{l}\mathrm{p}= \\
0.0000\end{array}$ \\
\hline & & $p=0,999$ & & & \\
\hline Cohen's d & & $d=-0.092$ & & & \\
\hline \multicolumn{6}{|l|}{ GR } \\
\hline A-PRF+ & $2.67 \pm 1.88$ & $3.93 \pm 2.73$ & $\begin{array}{l}\mathrm{p}< \\
0.0025\end{array}$ & $\begin{array}{l}1.26 \pm \\
1.33\end{array}$ & $\begin{array}{l}p= \\
0.0025\end{array}$ \\
\hline \multirow[t]{2}{*}{ EMD } & $2.47 \pm 1.46$ & $3.33 \pm 1.58$ & $\begin{array}{l}p< \\
0.0044\end{array}$ & $\begin{array}{l}0.86 \pm \\
0.99\end{array}$ & $\begin{array}{l}p= \\
0.0044\end{array}$ \\
\hline & & $p=0,469$ & & & \\
\hline Cohen's d & & $d=0.352$ & & & \\
\hline \multicolumn{6}{|l|}{ CAL } \\
\hline A-PRF+ & $\begin{array}{l}10.93 \pm \\
2.79\end{array}$ & $8.6 \pm 2.56$ & $\begin{array}{l}p< \\
0.0001\end{array}$ & $\begin{array}{l}-2.33 \pm \\
1.588\end{array}$ & $\begin{array}{l}p= \\
0.0001\end{array}$ \\
\hline \multirow[t]{2}{*}{ EMD } & $\begin{array}{l}10.60 \pm \\
1.76\end{array}$ & $8.00 \pm 1.77$ & $\begin{array}{l}p< \\
0.0001\end{array}$ & $-2.6 \pm 1.18$ & $\begin{array}{l}p= \\
0.0000\end{array}$ \\
\hline & & $p=0,461$ & & & \\
\hline Cohen's d & & $d=0.197$ & & & \\
\hline \multicolumn{6}{|l|}{ BS } \\
\hline A-PRF+ & $9.60 \pm 1.68$ & $5.67 \pm 0.89$ & $\begin{array}{l}p< \\
0,0001\end{array}$ & $\begin{array}{l}-3.93 \pm \\
1.98\end{array}$ & $\begin{array}{l}p= \\
0.0000\end{array}$ \\
\hline \multirow[t]{2}{*}{ EMD } & $9.47 \pm 1.68$ & $5.67 \pm 0.81$ & $\begin{array}{l}\mathrm{p}< \\
0,0001\end{array}$ & $-3.8 \pm 1.56$ & $\begin{array}{l}\mathrm{p}= \\
0.0000\end{array}$ \\
\hline & & $p=0,999$ & & & \\
\hline Cohen's d & & $d=-0.077$ & & & \\
\hline
\end{tabular}


Table 4

Frequency distribution of the results (intergroup comparison, $\mathrm{p}>0.999$ )

\begin{tabular}{|llll|}
\hline & A-PRF+ & EMD & total \\
\hline PD & & & \\
\hline decrease & 15 & 15 & 30 \\
\hline total & 15 & 15 & 30 \\
\hline GR & & & \\
\hline decrease & 0 & 1 & 1 \\
\hline no change & 5 & 4 & 9 \\
\hline increase & 10 & 10 & 20 \\
\hline total & 15 & 15 & 30 \\
\hline Fisher's exact & & & 1.000 \\
\hline CAL & & 15 & 28 \\
\hline decrease & 13 & 15 & 28 \\
\hline no change & 2 & 0 & 2 \\
\hline & 15 & 15 & 30 \\
\hline Fisher's exact & & & 0.483 \\
\hline BS & 15 & 15 & \\
\hline decrease & 14 & 14 & 28 \\
\hline no change & 1 & 1 & 2 \\
\hline & & & \\
\hline Fisher's exact & & & \\
\hline
\end{tabular}

After 6 months, the mean GR increase was $3.93 \pm 2.73 \mathrm{~mm}$ in the test group and $3.33 \pm 1.58 \mathrm{~mm}$ in the control group. The increase in GR was statistically significant for both groups $(p<0.01)$, but no difference between the groups was observed.

The mean CAL gain was $2.33 \pm 1.58 \mathrm{~mm}$ in the A-PRF + group and $2.60 \pm 1.18 \mathrm{~mm}$ in the EMD group ( $\mathrm{p}<$ 0.001). In both groups, the CAL has improved significantly compared to baseline, but no statistically 
significant difference was found between the two groups.

After 6 months, the mean BS has decreased to $5.67 \pm 0.89 \mathrm{~mm}$ in the test group and to $5.67 \pm 0.81 \mathrm{~mm}$ in the control group. Compared to baseline data $9.60 \pm 1.68 \mathrm{~mm}$ in the test group, respectively $9.47 \pm 1.68$ $\mathrm{mm}$ in the control group, the mean BS reduction was significant $(p<0.001)$, but no difference between the groups was observed, the results obtained with both materials were similar. (Table 3.)

\section{Discussion}

One of the main benefits of PRF is the fibrin network that promote not only blood clot formation but also tissue repair mechanisms [27]. Compared to PRP, the kinetics of growth factor release appear to be slower, thus affecting regeneration over a longer period of time [28]. More and more studies are drawing attention to the beneficial effect of leukocytes on healing as well as tissue regeneration, and not least the importance of the quality of the fibrin network. The leukocytes it contains have both anti-infective and immunoregulatory functions [29-32], but also produce significant amounts of VEGF [33]. These factors, in addition to platelet-derived angiogenesis-stimulating factors, may have a positive impact on proper blood supply of the healing wound. White blood cells are involved in the early stimulation of osteoprogenitor cells and promote the differentiation of monocytes into macrophages [16, 33-36].

Many controlled randomized clinical trials investigated the use of PRF for the repair/regeneration of periodontal intrabony defects [37-41]. All studies demonstrated that the additional application of PRF increased PD reductions and CAL gains compared to open flap debridement alone. In a recent publication the supplementation of PRF with EMD did not result in a difference between the study and control (EMD only) groups [42]. The efficacy of PRF and EMD in the treatment of intrabony defects was compared in a clinical and a cone beam computed tomography study. Based on the obtained results, both materials were effective in the treatment of intrabony defects, however EMD was significantly superior in terms of percentage defect resolution [43]. Although these clinical trials have all shown that the use of PRF results in statistically significant CAL gains and PD reduction, it is important to emphasize that histological examination would be necessary to confirm whether the obtained results correspond to a periodontal regeneration or a periodontal repair.

It has been demonstrated that the biological benefits of PRF act locally by rapidly stimulating a large number of cell types by influencing their recruitment, proliferation and/or differentiation [15]. Based on the available literature, it seems that PRF favours the regeneration of soft tissues rather than hard tissues [44]. In the treatment of intrabony defects where space maintenance is not an issue, blood clot formation alone could be enough [45], the additional use of PRF acts primarily as a scaffold, inserted into the periodontal pocket may promote tissue regeneration [17]. More research is needed to determine which factors in the PRF clots (cells/leukocytes, growth factors, or fibrin matrix) are most required to accelerate the regeneration of periodontal tissues.

Data from in vitro studies indicates that EMD may also influence periodontal wound healing by an indirect stimulatory effect on the release of growth factors during periodontal wound healing and by 
inhibiting or at least retarding epithelial down-growth [46].

The modification of the preparation protocol by reducing the applied centrifugation force (RCF), resulted in an improved preparation protocol for advanced PRF (A-PRF) using $208 \mathrm{~g}$ RCF. Compared to PRF the APRF clot showed a more porous structure with a larger interfibrous space, where cells (particularly platelets) were observed in even distributions throughout the entire clot, furthermore histological analysis of A-PRF has showed a significantly higher number of neutrophile granulocytes [44].

Described by Fujioka-Kobayashi et al., it has been found that the total growth factor release could be enhanced by reducing both centrifugation speed and time. A-PRF + showed similar porosity to A-PRF, furthermore over the entire clot the cellular distribution pattern it has showed evenly dispersed platelets. These observations emphasize the improved regenerative capacity of advanced PRF matrices [20].

The results of the present study obtained after six months post-surgically clearly indicate the significant improvement of the following parameters: PD, CAL, BS in both groups. No adverse reactions have been observed throughout the first six months, which clearly indicates that the use of autologus test material has been well tolerated.

As a result of surgery and cessation of inflammation, the rate of gingival recession became significantly higher in both groups compared to the baseline. Upon intergroup comparison the GR increase was found to be non-significantly different. The cause of gingival recession observed after periodontal surgery does not necessarily depend on the methods. However, the gingival biotype can significantly affect the extent of the recession. At the same time, a significant improvement in clinical probing pocket depth resulted in a significant enhancement of the clinical attachment level. In addition to the significant improvement of bone sounding values, radiographs taken with the "long-cone" technique also suggest the presence of bone filling. (Fig. 1.,2.)

There was no significant difference between the test and control groups in the first 6 months after surgery and the results obtained with both materials were similar. The amount of gingival recession seems to be lower in the control group. Thus, it appears that the clinical benefit of both treatments is not only treats intrabony defects, but also improves PD values by facilitating plaque control and maintenance. However, when interpreting these findings, we must keep in mind that currently no other data evaluating the treatment of intrabony defects with A-PRF+ / EMD is available. Therefore, direct comparisons with other studies are not possible at this point in time.

On the other hand, it also needs to be considered that the lack of a difference between the two groups can additionally be related to the rather limited number of treated defects (e.g. 15 defects in each group) and therefore, the study may not have the statistical power to rule out the possibility of a difference between the two groups. For superiority trials in the treatment of periodontal intrabony defects, a sample size of approximately 30 persons per group has been estimated to be required [47]. 
Finally, the present study using a new generation of PRF seems to open new horizons in the investigation of the effects of platelet-concentrates on periodontal healing. However, other randomized, clinical trials with a bigger population and with histological evaluation of periodontal regeneration will be necessary to confirm the results of this study.

\section{Conclusion}

In view of above findings and within the limitations of the current study, the results indicate that the newgeneration platelet rich fibrin behaves just as effectively as enamel matrix derivatives in the surgical treatment of intrabony periodontal defects. Based on the 6-month results, both methods resulted in comparable outcomes and presented no significant differences between the test and control groups. A$\mathrm{PRF}+$ seems to be suitable for the treatment of intrabony periodontal defects.

\section{List Of Abbreviations}

A-PRF: advanced platelet-rich fibrin

EMD: enamel matrix derivative

PRP: platelet-rich plasma

PRG: platelet-rich gel

PRF: platelet-rich fibrin

GDF's: growth and differentiation factors

CAP: concentrated autologous products

PDGF: platelet-derived growth factor

TGF- $\beta$ : transforming growth factor beta

L-PRF: leukocyte- and platelet-rich fibrin

EGF: epidermal growth factor

IGF: insulin-like growth factor

VEGF: vascular endothelial growth factor

rhGF: recombinant human growth factors

PD: probing depth 
GR: gingival recession

CAL: clinical attachment level

BS: bone sounding

FMBS: full-mouth bleeding score

FMPS: full-mouth plaque score

EDTA: ethylenediamine tetraacetic acid

\section{Declarations}

\section{Ethics approval and consent to participate}

This study was planned as a randomized, controlled, prospective clinical trial. All procedures performed in studies involving human participants were in accordance with the ethical standards of the institutional and/or national research committee and with the 1964 Helsinki declaration and its later amendments or comparable ethical standards. The protocol was approved by the ethics committee of the Semmelweis University Budapest (approval number: SE TUKEB: 254/2017). The study protocol was registered at ClinicalTrials.gov with ID number NCT04404374.

All the included patients signed an informed consent which was previously approved by an institutional ethic committee.

\section{Consent for publication}

Written informed consent for publication was obtained.

\section{Availability of data and materials}

Authors can confirm that all relevant data are included in the article and/or its supplementary information files.

\section{Competing interests}

The authors declare that they have no competing interests.

\section{Funding}

The study materials have been procured as a result of a tender organized by the Semmelweis University, School of Dental Medicine, Budapest, Hungary.

\section{Authors' contributions}


BCsN participated in the design of the study, carried out surgical procedures, analysis and interpretation of data and drafting the manuscript. ES contributed to acquisition of data. VLB contributed to patient administration. AN contributed to pre-and postsurgical periodontal management. FD had the main responsibility for conception and design of the study, involved in drafting the manuscript and revising it critically for important intellectual content. All authors read and approved the final version of the manuscript.

\section{Acknowledgements}

The authors acknowledge to Laszlo Dr Kardos, who performed the statistical analysis and contributed to interpretation of data.

\section{References}

1. Sculean A, Nikolidakis D, Nikou G, Ivanovic A, Chapple IL, Stavropoulos A: Biomaterials for promoting periodontal regeneration in human intrabony defects: a systematic review. Periodontol 2000. 2015, Jun;68(1):182-216. doi: 10.1111/prd.12086. PMID: 25867987.

2. Bosshardt DD, Sculean A: Does periodontal regeneration really work? Periodontol 2000. 2009, 51:208-219.

3. Hammarström L, Heijl L, Gestrelius S: Periodontal regeneration in buccal dehiscence model in monkeys after application of enamel matrix proteins. J Clin Periodontol. 1997, 24:669-677. DOI: 1111/j.1600-051x.1997.tb00248.x

4. Sculean A: Periodontal regenerative therapy, Quintessence Publishing. 2010, chapter 13:194-209.

5. Sculean A, Schwarz F, Miliauskaite A et al: Treatment of intrabony defects with an enamel matrix protein derivative or bioabsorbable membrane: An 8-year follow-up split-mouth study. J Periodontol. 2006, 77:1879-1886. DOI: 1902/jop.2006.060002

6. Sculean A, Schwarz F, Chiantella GC, Arweiler NB, Becker J: Nine-year results following treatment of intrabony periodontal defects with an enamel matrix derivative: Report of 26 cases. Int J Periodontics Restorative Dent. 2007, 27:221-229.

7. Sculean A, Kiss A, Miliauskaite A, Schwarz F, Arweiler NB, Hannig M: Ten-year results following treatment of intra-bony defects with enamel matrix proteins and guided tissue regeneration. $J$ Clin Periodontol. 2008, 35:817-824. DOI: 1111/j.1600-051X.2008.01295.x

8. Iorio-Siciliano V, Blasi A, Nuzzolo P, Matarasso M, Isola G, Ramaglia L: Treatment of Periodontal Intrabony Defects Using Enamel Matrix Derivative: Surgical Reentry After an Observation Period of at Least 5 Years. Int J Periodontics Restorative Dent. 2019, Jul/Aug;39(4):537-543. doi: 10.11607/prd.4148. PMID: 31226192.

9. Choukroun J, Adda F, Schoeffler C, Vervelle A: Une opportunité en paro-implantologie: le PRF. 2001, 42(55):e62. 
10. Camargo PM, Lekovic V, Weinlaender M, Vasilic N, Madzarevic M, Kenney EB:Platelet-rich plasma and bovine porous bone mineral combined with guided tissue regeneration in the treatment of intrabony defects in humans. J Periodontal Res. 2002, 37(4):300-6. doi: 10.1034/j.16000765.2002.01001.x.

11. Okuda K, Tai H, Tanabe K, et al: Platelet-rich plasma combined with a porous hydroxyapatite graft for the treatment of intrabony periodontal defects in humans: A comparative controlled clinical study. J Periodontol. 2005, 76:890-898.

12. Dőri $F$ et al: Effect of platelet-rich plasma on the healing of intrabony defects treated with a natural bone mineral and a collagen membrane. J Clin Periodontol. 2007, 34(3):254-61. DOI: 1111/j.1600051X.2006.01044.X

13. Miron R: Platelet Rich Fibrin in Regenerative Dentistry, Wiley Blackwell Publishing. 2017, chapter 9: 127-137.

14. Marx RE: Platelet-rich plasma: evidence to support its use. J Oral Maxillofac Surg. 2004, 62(4):48996. DOI: 1016/j.joms.2003.12.003

15. Marx RE et al: Platelet-rich plasma: Growth factor enhancement for bone grafts. Oral Surg Oral Med Oral Pathol Oral Radiol Endod. 1998, 85(6):638-46. DOI: 1016/s1079-2104(98)90029-4

16. Choukroun J, Diss A, Simonpieri A, Girard MO, Schoeffler C, Dohan SL et al: Platelet-rich fibrin (PRF): a second-generation platelet concentrate. Part IV: clinical effects on tissue healing. Oral surgery, oral medicine, oral pathology, oral radiology, and endodontics. 2006, 101(3):56-e60. DOI: 1016/j.tripleo.2005.07.011

17. Dohan DM et al: Platelet-rich fibrin (PRF): a second-generation platelet concentrate. Part II: plateletrelated biologic features. Oral Surg Oral Med Oral Pathol Oral Radiol Endod. 2006, 101(3):45-50. DOI: 1016/j.tripleo.2005.07.009

18. Ghanaati S, Booms P, Orlowska A, Kubesch A, Lorenz J, Rutkowski J, Landes C, Sader R, Kirkpatrick C, Choukroun J: Advanced Platelet-Rich Fibrin: A New Concept for Cell-Based Tissue Engineering by Means of Inflammatory Cells, J. Oral Implantol. 2014, 40:679-DOI: 10.1563/aaid-joi-D-14-00138

19. Cabaro S, D'Esposito V, Gasparro R, Borriello F, Granata F, Mosca G, Passaretti F, Sammartino JC, Riccitiello F, Beguinot F, Formisano P, Sammartino G: White cell and platelet content affects the release of bioactive factors in different blood-derived scaffolds. Platelets . 2017, 21:1-5. DOI: 1080/09537104.2017.1319046

20. Fujioka-Kobayashi M, Miron RJ, Hernandez M, Kandalam U, Zhang Y, Choukroun J: Optimized Platelet-Rich Fibrin With the Low-Speed Concept: Growth Factor Release, Biocompatibility, and Cellular Response. J Periodontol. 2017, 88:112-121. DOI: 1902/jop.2016.160443

21. Tonetti MS, Greenwell H, Kornman KS: Staging and grading of periodontitis: framework and proposal of a new classification and case definition. J Periodontol. 2018, 89:S159-72. DOI: 1002/JPER.180006

22. Tonetti MS, Pini-Prato GP, Cortellini P: Effect of cigarette smoking on periodontal healing following GTR in infrabony defects. A preliminary retrospective study. J Clin Periodontol. 1995, 22:229- 
234.DOI: 1111/j.1600-051x.1995.tb00139.x

23. Cortellini P, Prato GP, Tonetti M: Periodontal regeneration of human infrabony defects. I. Clinical measures. J Periodontol. 1993, 64:254-260. DOI: 1902/jop.1993.64.4.254

24. O'Leary TJ, Drake RB, and Naylor JE : The Plaque Control Record. Journal of Periodontology. 1972, 43(1):38-38. DOI: 1902/jop.1972.43.1.38

25. Cortellini P, Tonetti M: Radiographic defect angel influences the outcome of GTR therapy in intrabony defects. J Dent Res. 1999, 78:381.

26. Blomlöf JPS, Blomlöf LB, Lindskog SF: Smear removal and collagen exposure after non-surgical root planing followed by etching with an EDTA gel preparation. J Periodontol . 1996, 67:841-845.DOI: 1902/jop.1996.67.9.841

27. Toffler M, Toscano N, Holtzclaw D, Corso M, Dohan D: Introducing Choukroun's platelet rich fibrin (PRF) to the reconstructive surgery milieu. J Implant Adv Clin Dent. 2009, 1:22-31.

28. Kobayashi E, Fluckiger L, Fujioka-Kobayashi M, Sawada K, Sculean A, Schaller B, et al: Comparative release of growth factors from PRP, PRF, and advanced-PRF. Clinical Oral Investigations. 2016, 20(9):2353-2360.DOI: 1007/s00784-016-1719-1

29. Dohan DM et al: Platelet-rich fibrin (PRF): a second-generation platelet concentrate. Part III: leucocyte activation: a new feature for platelet concentrates? Oral Surg Oral Med Oral Pathol Oral Radiol Endod. 2006, 101(3):51-55.DOI: 1016/j.tripleo.2005.07.010

30. Everts PA et al: What do we use: platelet-rich plasma or platelet-leukocyte gel? J Biomed Mater Res A. 2008, 85:1135-1136.

31. Cieslik-Bielecka A et al: Why the platelet-rich gel has antimicrobial activity? Oral Surg Oral Med Oral Pathol Oral Radiol Endod. 2007, 103:303-305.DOI: 1016/j.tripleo.2006.08.034

32. Moojen DJ et al: Antimicrobial activity of platelet-leukocyte gel against Staphylococcus aureus. J Orthop Res. 2008, 26:404-410.DOI: 1002/jor.20519

33. Werther $\mathrm{K}$ et al. Determination of vascular endothelial growth factor (VEGF) in circulating blood: significance of VEGF in various leucocytes and platelets. Scand J Clin Lab Invest . 2002, 62:343-350. DOI: 1080/00365510260296492

34. Ghanaati S, Booms P, Orlowska A, Kubesch A, Lorenz J, Rutkowski J, Landes, Sader R, Kirkpatrick C, Choukroun J: Advanced platelet-rich fibrin: a new concept for cell-based tissue engineering by means of inflammatory cells. J Oral Implantol. 2014, 40:679-89. DOI: 1563/aaid-joi-D-14-00138

35. Kawase T et al: Platelet-rich plasma-derived fibrin clot formation stimulates collagen synthesis in periodontal ligament and osteoblastic cells in vitro. J Periodontol. 2003, 74:858-864.DOI: 1902/jop.2003.74.6.858

36. Clark RA: Fibrin and wound healing. Ann of the New York Academy of Sciences. 2001, 936:355-67. DOI: 1111/j.1749-6632.2001.tb03522.x

37. Sharma A and AR Pradeep: Treatment of 3-wall intrabony defects in patients with chronic periodontitis with autologous platelet-rich fibrin: a randomized controlled clinical trial. J Periodontol. 
2011, 82(12):1705-12.DOI: 1902/jop.2011.110075

38. Thorat M, AR Pradeep, and B Pallavi: Clinical effect of autologous platelet-rich fibrin in the treatment of intrabony defects: a controlled clinical trial. J Clin Periodontol. 2011, 38(10):925-32.DOI: 1111/j.1600-051X.2011.01760.x

39. Pradeep AR et al: Comparative evaluation of autologous platelet-rich fibrin and platelet-rich plasma in the treatment of 3-wall intrabony defects in chronic periodontitis: a randomized controlled clinical trial. J Periodontol. 2012, 83(12):1499-507.DOI: 1902/jop.2012.110705

40. Ajwani H, Shetty S, Gopalakrishnan D, Kathariya R, Kulloli A, Dolas RS, et al. Comparative evaluation of platelet-rich fibrin biomaterial and open flap debridement in the treatment of two and three wall intrabony defects. Journal of International Oral Health: JIOH. 2015, 7(4): 32-37. PMCID: PMC4409793

41. Patel GK, Gaekwad SS, Gujjari SK: Platelet-Rich Fibrin in Regeneration of Intrabony Defects: A Randomized Controlled Trial. J Periodontol. 2017, 88(11):1192-1199. DOI: 1902/jop.2017.130710

42. Aydemir Turkal H, Demirer S, Dolgun A, Keceli HG: Evaluation of the adjunctive effect of platelet-rich fibrin to enamel matrix derivative in the treatment of intrabony defects. Six-month results of a randomized, split-mouth, controlled clinical study. Journal of Clinical Periodontology. 2016, 43(11):955-64. DOI: 1111/jcpe.12598

43. Gupta SJ, Jhingran R, Gupta V, Bains VK, Madan R and Rizvi I: Efficacy of platelet-rich fibrin vs. enamel matrix derivative in the treatment of periodontal intrabony defects: a clinical and cone beam computed tomography study. J Int Acad Periodontol. 2014, 16:86-96.

44. Miron RJ, Fujioka-Kobayashi M, Bishara M, Zhang Y, Hernandez M, Choukroun J: Platelet-Rich Fibrin and Soft Tissue Wound Healing: A Systematic Review. Tissue engineering Part B, Reviews. 2017 Feb;23(1):83-99. DOI: 1089/ten.TEB.2016.0233

45. Cortellini T, Tonetti M: Improved wound stability with a modified minimally invasive surgical technique in the regenerative treatment of isolated interdental intrabony defects. J Clin Periodontol. 2009, 36(2):157-63. DOI: 1111/j.1600-051X.2008.01352.x

46. Van der Pauw MT, Van den Bos T, Everts V and Beertsen W: Enamel matrix-derived protein stimulates attachment of periodontal ligament fibroblast and enhances alkaline phosphatase activity and transforming growth factor b1 release of periodontal ligament and gingival fibroblasts. Journal of Periodontology. 2000, 71:31-43.

47. Gunsolley JC, Elswick RK and Davenport JM: Equivalence and superiority trials in regeneration clinical trials. Journal of Periodontology. 1998, 69:521-527. DOI: 1902/jop.1998.69.5.521

\section{Figures}



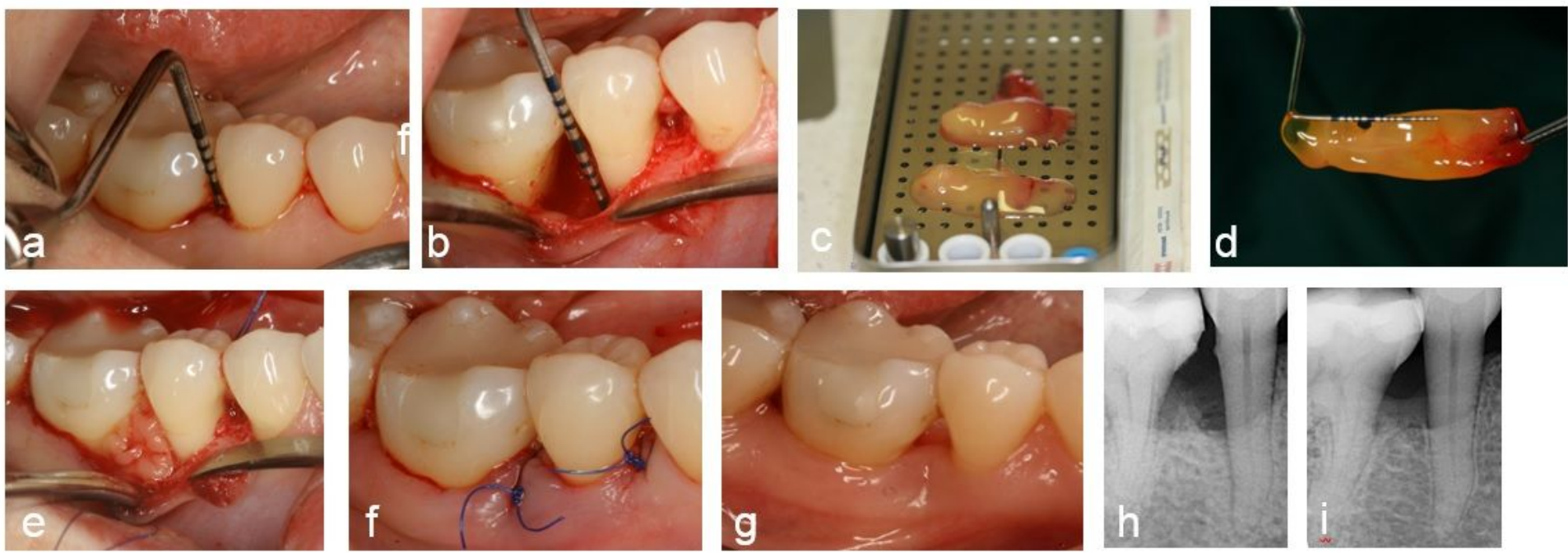

\section{Figure 1}

Treatment of an intrabony defect at a lawer jaw premolar with A-PRF+ a - Preoperative measurements b Defect after debridement - intraoperative measurements $\mathrm{C}$ - Product after centrifugation in the PRF Box (Process for PRF $\AA$ ) $d$ - Prepared product (RBC + A-PRF+) e - Intrabony defect filled with A-PRF+ $f$ - Wound closure g - 6 months after surgery $\mathrm{h}$ - $\mathrm{i}$ - Radiographic evaluation before and 6 months after surgery
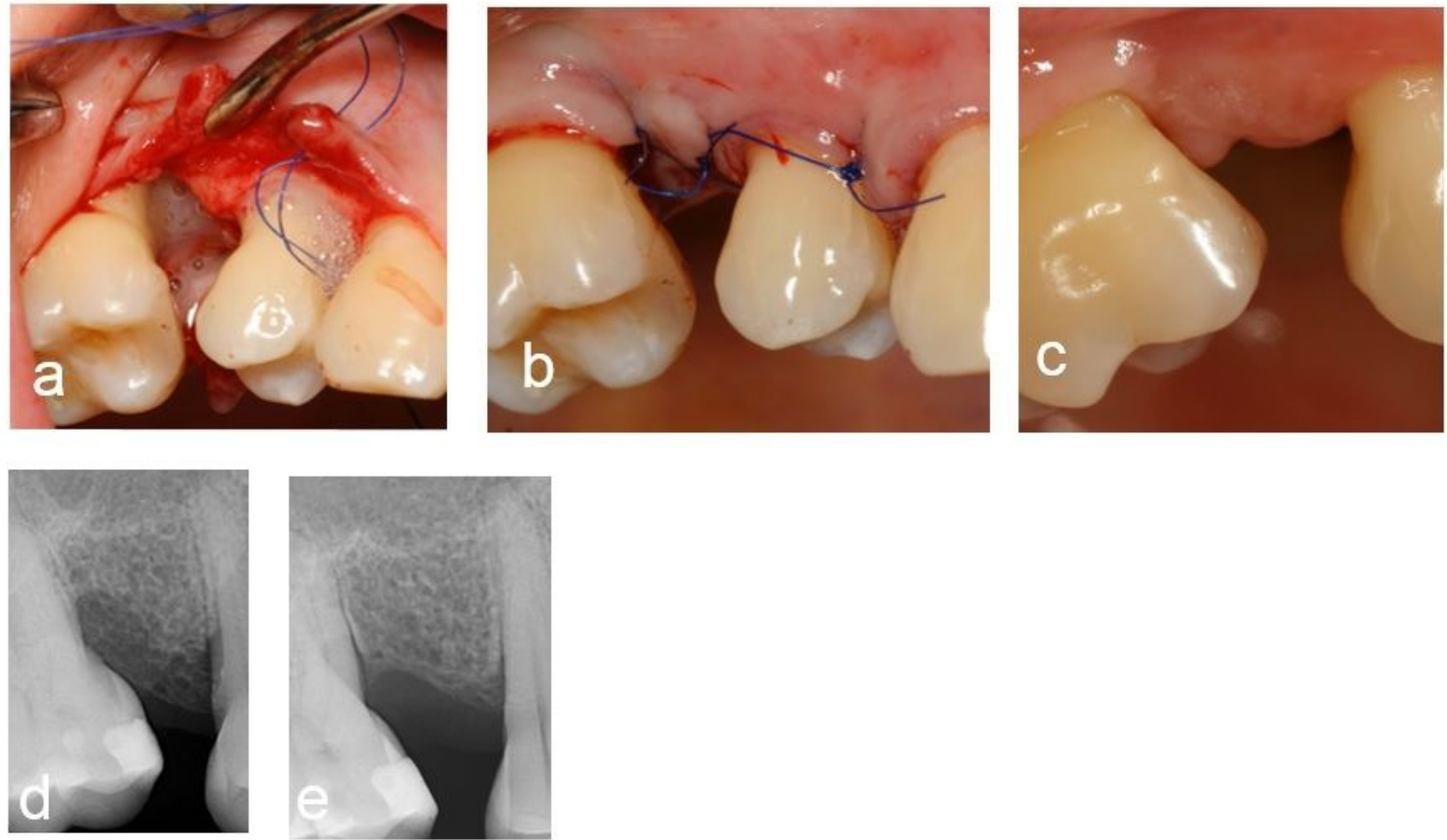

Figure 2 
Treatment of an intrabony defect at an upper jaw molar with EMD a - Defect after debridement - intrabony defect filled with EMD b - Wound closure c - 6 months after surgery $d$ - e - Radiographic evaluation before and 6 months after surgery

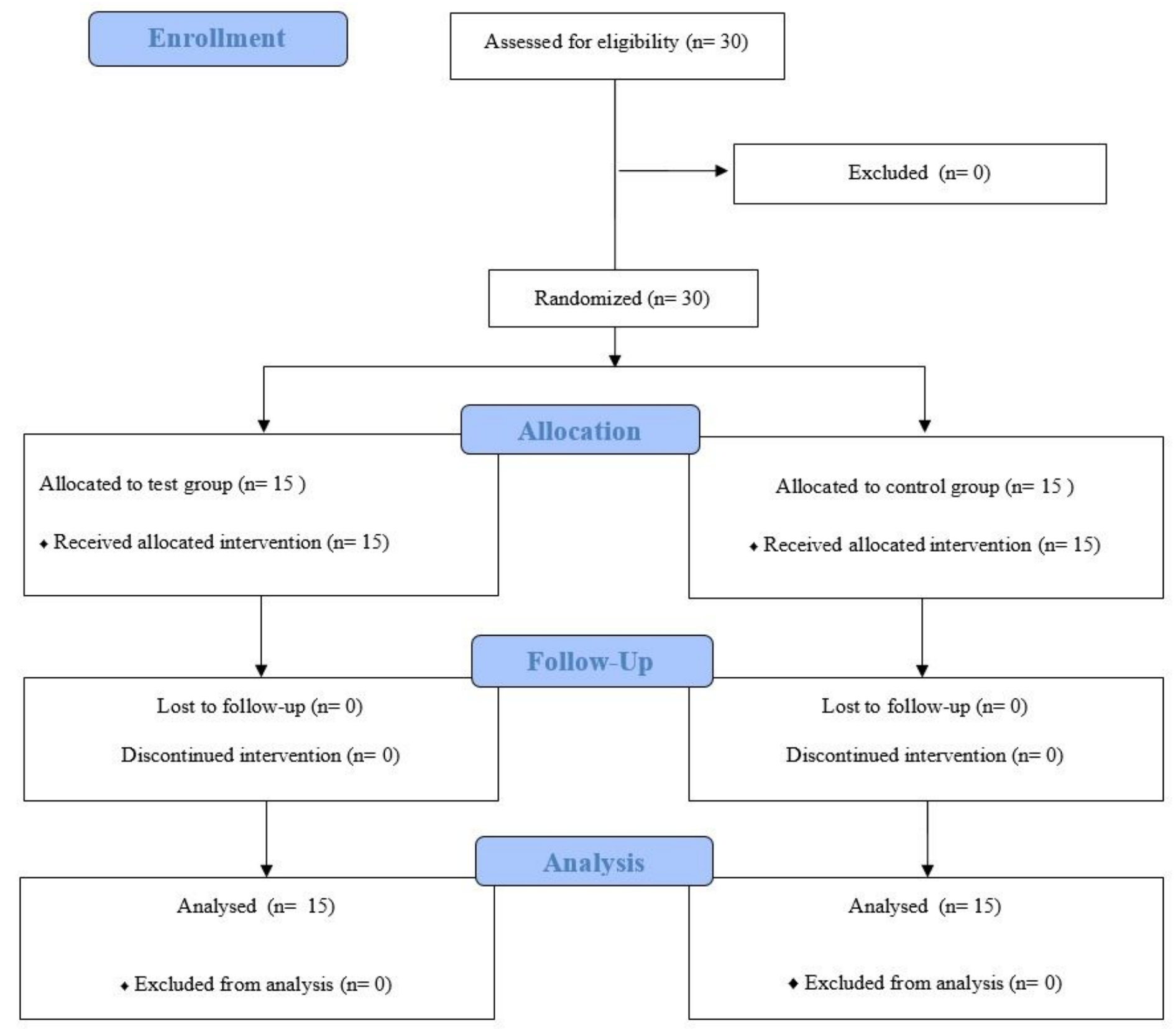

Figure 3

Flow diagram of patient enrollment and study process

\section{Supplementary Files}

This is a list of supplementary files associated with this preprint. Click to download.

- CONSORT2010Checklist.docx 